\title{
Conformational Analysis of Humic Acids from Amazonian Dark Earth Soils observed by AFM
}

\author{
F. L. Leite ${ }^{1, *}$, D. K. Deda ${ }^{1}$, M. L. Simões ${ }^{2}$, W. T. L. da Silva ${ }^{2}$, L. Martin-Ne to ${ }^{2}$, T. J. F. da Cunha ${ }^{3}$ \\ ${ }^{1}$ University of São Carlos (UFSCar), 18052-780, Sorocaba -SP, Brazil \\ ${ }^{2}$ Embrapa Agricultural Instrumentation, National Nanotechnology Laboratory for Agriculture, P. O. Box 741, 13560-970, São Carlos, SP, \\ Brazil \\ ${ }^{3}$ Embrapa Tropical Semi-Arid Center (CPATSA), BR 428, Km 152, Zona Rural, P. O. Box 23, 56302970, Petrolina-PE, Brazil
}

\begin{abstract}
Conformational analysis of humic acid (HA), extracted from an A mazon anthropogenic soil and an adjacent soil which did not have anthropogenic A horizon, was done by atomic force microscopy (AFM), through the deposition of humic acid layers on muscovite mica strips using drop-casting deposition technique. This short communication presents, for the first time, AFM images of the sub-micron level structure of humic acid of the A mazonian Dark Earths, compared to natural pedogenic Amazonian soil. The adsorbed anthropogenic HA form ring-shaped aggregates with diameters on the scale of several tens of nanometers, possibly showing evidences of a supramolecular formation. The formation of these structures was not verified for HA from pedogenic soil. In this case, it was observed particles with globular shape and a homogenous distribution of them on the mica surface. Structural characteristics of each sample were observed by nuclear resonance magnetic spectroscopy (NMR). The spectra analysis indicated that pedogenic HA are richer in aliphatic groups, as methoxylic and in polysaccharides structures, while the higher concentrations of aro matic carbon, including also phenolic carbon, were observed in the anthropogenic HA, justifying its higher hydrophobic character.
\end{abstract}

Keywords Humic Acid, Atomic Force Microscopy, Anthropogenic Soil, Supramolecular Structures, Amazon Dark Earth, Nuclear Resonance Magnetic

\section{Introduction}

Soil Organic Matter (SOM) play an important role on many aspects of the nature of soil and environmental processes. Humic Substances (HS) are the major organic constituents of soils and aquatic environments and are generated by the microbiological and chemical degradation, and transformation of organic matter (OM), resulting in chemical structures which are more stable than the starting material[1-4]. Most of the soils in the Amazon Basin are acidic, with low cation-exchange capacity, fertility and production potential. In this environment, where soil fertility is a limiting factor for sustainable agricultural development, occurs the "Terra Preta de Índio" soil[5], also known as Amazonian Dark Earth, Anthropogenic Dark Earth, Indian Black Earths, or Archaeological Dark Earths. These soils, that have an archeo-anthropedogenic horizon, which is a surface horizon with variable depth in soil profiles, exhibit elevated OM contents and either ceramic pieces or lithic artifacts [6]. The OM present in these soils shows high stability and reactivity characteristics[7]. The orig in of th is $\mathrm{OM}$ is thought to be

* Corresponding author:

fabioleite@u fs car.br (F. L. Leite)

Published online at http://journal.sapub.org/scit

Copyright (C) 2012 Scientific \& Academic Publishing. All Rights Reserved mostly pyrogenic and is related to the domestic/agricultural activity of pre-columbian populations that colonized the Amazon basin since 3000 B.C.[8]. Due to its high fertility, compared to the adjacent soils, it is has been frequently used in subsistence agriculture (beans, corn, etc.) and/or for commercial production of a high diversity of products (papaya, coconut, cupuaçu etc.).

The chemical nature and reactivity of HS are still little understood. Several researchers [9-11] have suggested a new model for structure of HS, in which small and heterogeneous humic molecules are self-assembled in supramolecular conformations stabilized only by weak forces. Several techniques have been employed to characterize the size, shape, conformation, structure and composition of HS. Fluorescence spectroscopy, for example, has become widely recognized as a relatively simple, sensitive, and powerful tool for the evaluation of humification[12,13] and the molecular size of humic substances[14,15]. Nuclear Ressonance Magnetic also is common ly used to characterize co mplex HS including humic and fulvic acids[16-19]. In addition, other techniques such as capillary electrophoresis[20], ultraviolet and infrared spectroscopy[21,22] and scanning electron microscopy (SEM)[23] have also been frequently employed.

Atomic Force Microscopy (AFM) technique can image surfaces with atomic resolution by scanning a sharp tip across the surface at forces smaller than the forces between 
atoms[24]. AFM has been employed to study the morphologies of humic and fulvic acid[25-28] and it is a powerful tool to characterize small colloids, as well as colloid agglomeration, adsorption onto surfaces, or modification in the morphologies, affected by changes in the physical-chemistry properties. Namjesnik-Dejanovic and Maurice[29] reported that high or low concentrations of fulvic acids, from river water, result in different structures, which can be differentiated by AFM. Chen and coworkers[30] combined AFM with SEM to investigated macromolecular structures of humic substances They reported that, depending on the $\mathrm{pH}$ and ionic strength of the initial solutions, humic substances deposited on mica and silica, adopted different spherical and large-area is land conformations.

In a general way, a better understanding of HS structures will provide information of origin and genesis, reactivity, and role in environmental processes. The objective of this work was to study the anthropogenic soil humic acid in comparis on to an adjacent soil which did not have anthropogenic A horizon, using AFM and, complementally, NMR. The purpose of our investigation was to obtain new data of morphology, adsorption and orientation of HA structures on mica from anthropogenic HA and shows evidences from supramolecular formation for the first time in Amazonian Dark Earth.

\section{Material and Methods}

Hu mic acids (HA) from two different orig ins, pedogenic and anthropogenic soil, both obtained from the Amazon State (Brazil), were extracted and purified according to the International Humic Substances Society (IHSS) method[31]. Suspensions of $100 \mathrm{mg} \mathrm{L}^{-1}$ of HA from anthropogenic Dark Earths and adjacent soil, were prepared suspending HA samples in deionized water. The suspension was shaken for at least three days. The $\mathrm{pH}$ was adjusted to $3.5 \mathrm{using} \mathrm{HCl}$. Muscovite mica with a surface area of about $1 \mathrm{~cm}^{2}$ was cleaved and kept into a Beaker containing $10 \mathrm{ml}$ of a $100 \mathrm{mg}$ $\mathrm{L}^{-1} \mathrm{HA}$ suspension for 1 day, under constant stirring. The mica was then rinsed with deionized water, put in a Petri $d$ ish and kept in a diseccator for 12 hours before obtaining the AFM images[32]. Unrinsed samples were also analyzed and used as comparison.

NMR experiments were performed with a Varian model Unity Inova 400 Spectrometer $\left({ }^{13} \mathrm{C}\right.$ resonance frequency of 100.58 MHz), equipped with a solid Doty Supersonic probe. The HA samples (approximately $300 \mathrm{mg}$ ) we re conditioned in a zirconium cylindrical rotor with $5 \mathrm{~mm}$ of external diameter (Doty Supersonic). The variable amplitude cross polarization magic angle spinning technique (VACP-MAS $\left.{ }^{13} \mathrm{C} \mathrm{NMR}\right)[33$ ] was applied with a contact time of $1 \mathrm{~ms}$, acquisition time of $12.8 \mathrm{~ms}$, pulse delay of $500 \mathrm{~ms}$, spinning speed of $6 \mathrm{kHz}$. The ${ }^{13} \mathrm{C}$ chemical shifts were referenced using hexametylbenzene - the resonance line in $17.2 \mathrm{ppm}$.

AFM imaging were obtained at room temperature, using an Atomic Force Microscope TMX 2010 Topometrix, in- cluding special silicon nitride $\left(\mathrm{Si}_{3} \mathrm{~N}_{4}\right)$ cantilevers with spring constant of $0,032 \mathrm{~N} \mathrm{~m}^{-1}$ and pyramidal tip with radius of 40 $\mathrm{nm}$. To investigate the samples with AFM, it was used the contact mode tip and scan rate of $1.5 \mathrm{~Hz}$. Surface scans of AFM were analyzed using a freeware scanning probe microscopy software based on MS-Windows named WSXM[34].

\section{Results and Discussions}

A typical image of pedogenic HA adsorbed on mica surface is shown in Figure 1a. The globular and cone-shaped features were assigned to islands of HA adsorbed on mica surface, and were identified two general types of structures, which can be summarized as: particles or spheroids and network of particles. AFM images show that large aggregates and small particles coexisted. The $\mathrm{pH}$ of HA suspension (3.5) favors the aggregate conformation due to a shielding of charges of functional groups and, under these conditions, intermo lecular interactions between the particles are also favored[35].

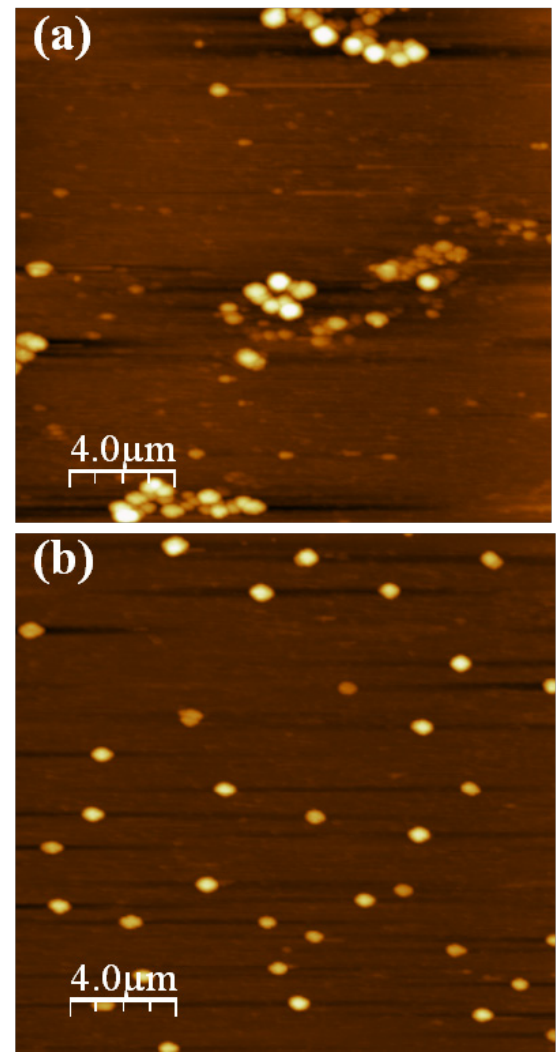

Figure 1. Contact mode AFM images $(20 \times 20 \mu \mathrm{m})$ of pedogenic humic acid $(\mathrm{pH}=3.5)$ adsorbed on mica surface. (a) unrinsed and (b) rinsed

Statistical bearing analysis was performed on different samples, over the entire scan area, to evaluate the effect of the rinsing procedure on the configuration of adsorbed pedogenic HA structures and the formation of adsorbed HA layers. On the rinsed surface it was also observed spheroids or isolated cone-shaped islands with smaller grain (Figure 1b). This image shows individual HA structures and reveal 
that the molecules have a globular shape and are fairly homogenous distributed on the surface. Freshly cleaved mica surface was also scanned under similar conditions and a smooth and flat surface of mica was observed. The cone shape was partially caused by the pyramidal shape of the AFM tip[36]. For each sample, five random positions were imaged, some of them with different magnifications, so that the selected image is very representative.

An image of anthropogenic HA adsorbed on mica surface is shown in Figure 2. The adsorbed HA structures in both sample-treatment methods (see Figure 2a and 2b) formed is lands with sub-mic ron size. In the unrinsed sample (Figure 2a) continuous HA layers, in ring format, were observed. The is lands of the unrinsed sample were significantly larger than those found in the rinsed ones. These homogeneous ring structures (see Figure 2c), formed at low salt concentration and low $\mathrm{pH}$ values, indicate evidences of supramolecular structures of HA in the natural environment and are strongly depending of the washing method. The quasi-continuous arrangements of the HA adsorbed on mica, before rinsing procedure, is a characteristic of supramolecular structures, which s mall particles or molecules interact forming a large structure. If the structure was composed of isolated molecules, the rinsing procedure make either total removing of the HA from mica surface or keep the initial structure, with small changes.

Figure $2 \mathrm{~b}$, obtained after the rinsing process, shows some spherical and aggregates of HA structures, with apparent colloidal diameters $<500 \mathrm{~nm}$. The image of a mica surface is very smooth and the adsorption of HA on the mica is quite clear. The size and shape of the spherical colloids are in agreement with those observed in the Figure 1 and with reports from other research groups for similar $\operatorname{HS}[30,35]$. However, neither ring structure nor hole in the middle of the structure was found in these works.
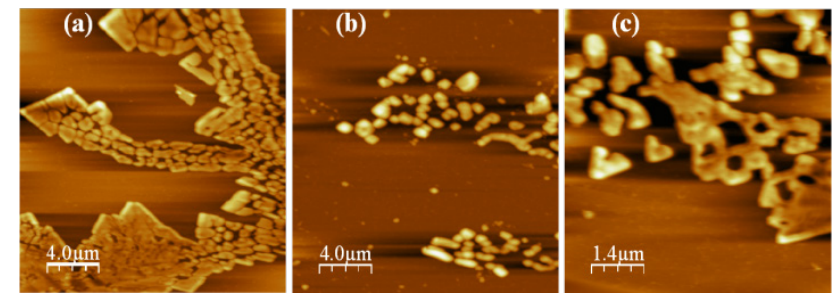

Figure 2. Contact mode AFM image $(20 \times 20 \mu \mathrm{m})$ of anthropogenic humic acid (a) unrinsed, (b) rinsed and (c) zoom-in from Figure 2a showing ring-type structures $(7 \times 7 \mu \mathrm{m})$

It should be noted that these shaped-ring structures were never observed in rinsed sample. This behavior can be due to two facts: (1) the air-drying process at room temperature was slow, possibly allowing lateral movement and stretching of the HA structures along the mica surface and (2) hydrophobicity effect. In the case 1 , the adsorption of HA molecules tends to follow the orientation of the plates between the atomic layers of the mica surface. In these plates, the lowest interfacial energy could be maintained, and the interaction between the HA molecules and hydrophilic mica surface results in orientations that maximize the contact area at the solid/liquid interface[36].

However, the hydrophobic character (case 2) of humic material, represented by hydrophobic compounds (long alky l-chain alkanes, alkenes, fatty acids, sterols, terpenoids, and phenyl-alkyl residues of lignin degradation), allows their self-association into supramolecular structures separated from the water medium.

This behavior describes a modern structural description regards humic material as a supramolecular structure[37], constituted of relatively small bio-organic molecules self-as sembled main ly by weak dispersive forces such as van der Waals force, $\pi-\pi, \mathrm{CH}-\pi$ and hydrogen bonds, building apparently large molecular chains. VACP-MAS ${ }^{13} \mathrm{C}$ NMR spectra of pedogenic and anthropogenic HA, presented in Figure 3, shows a similar features of soils HS[17, 38], which can be observed in five regions of distinct chemical shifts: C-alkyl (0-45 ppm), metoxil (45-60 ppm), O-alkyl/di-O-alkyl (60-110 ppm), C-aromatic (110-160), ${\mathrm{C}-\mathrm{COO}^{-}}^{-}$(160-185 ppm) and ${\mathrm{C}-\mathrm{CO}^{-}}^{-}$(185-245 ppm). One observes that pedogenic HA are richer in aliphatic groups, methoxylic and in polysaccharides structures, while the higher concentrations of aromatic carbon, including also phenolic carbon, were observed in the anthropogenic HA. This larger hydrophobic character in anthropogenic HA can explain the behavior observed in the Figure $2 \mathrm{a}$.

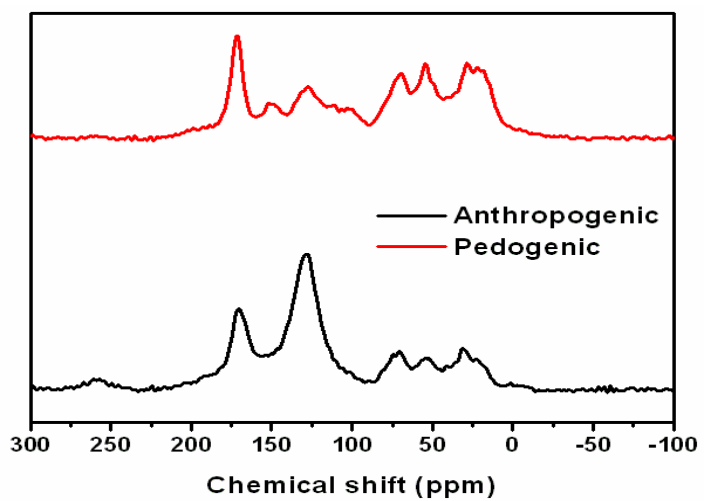

Figure 3. VACP-MAS ${ }^{13} \mathrm{C}$ NMR spectra of the pedogenic and anthropogenic humic acids

From the sectional analysis results, shown in Figure $4 \mathrm{a}$ and $4 \mathrm{~b}$, it is observed that the average dimensions of these rings range is fro $\mathrm{m}$ about 350 to $550 \mathrm{~nm}$ in lateral dimension and 60 to $130 \mathrm{~nm}$ in height. In the Figure 4b, the images illustrate a cut along the solid line shows the vertical profile. The sizes and shapes of the particles are not uniform for all the aggregates, which suggest that the aggregation of HA structures is optional and spontaneous. These homogeneous ring structures, formed in low $\mathrm{pH}$ values, again indicate evidences of supramolecular arrangements. In view to this, the results are apparently more consistent with the model of HA as sociation of small mo lecules [37].

It is worth reminded that aggregation process of HS is still poorly understood[39]. These properties of HS still a topic of debate between HS scientists. Divergent descriptions of HS defended by its proponent have been reviewed by Clapp and Hayes $[40,41]$. The challenge of consolidating a fully ac- 
cepted structural model to HS remains. The macro mo lecular model[42], until recently well accepted, has been extensively questioned and a supramolecular model was proposed[9] and diverged yet[41, 43]. Additional efforts must be created to have a definitive structural model for HS and spectroscopic and microscopic methods combined with other analytical tools to secure an important role in this endeavor.

(a)
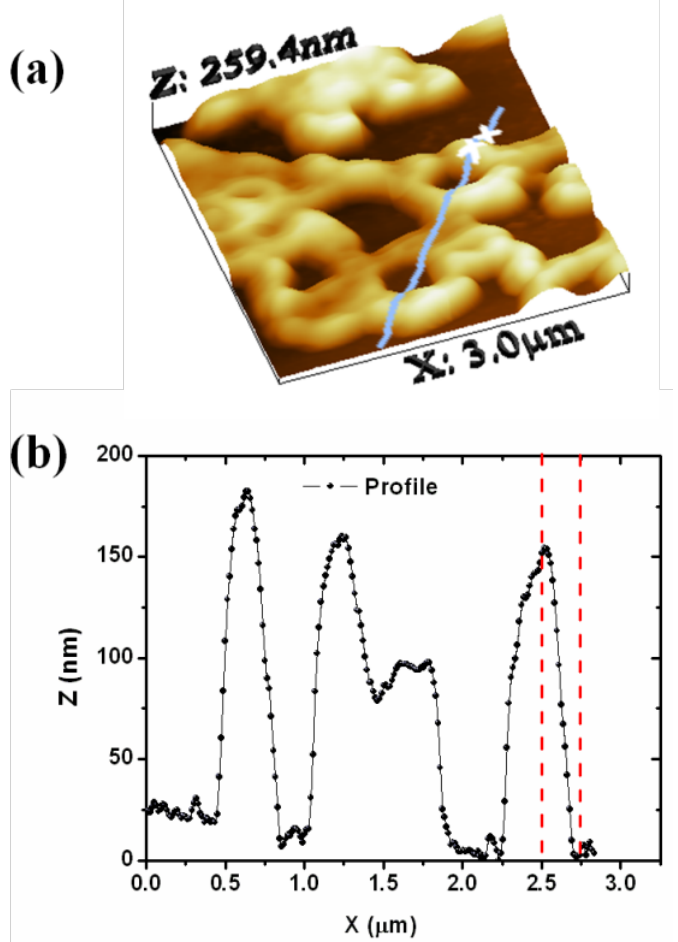

Figure 4. (a) 3 -D perspective view of a ring-type structure $(3 \times 3 \mu \mathrm{m})$ and (b) result of section analysis for humic acid adsorbed on mica

\section{Conclusions}

AFM was successfully used to measure HA adsorption on a mica surface. The results gave evidence that structure formation in thin HA films can be caused by dewetting during film deposition, and solution physical-chemistry. Under the experimental conditions used in this study, the adsorbed molecules form ring-shaped aggregates with diameters on the scale of several tens of nanometers; smaller nanometer-scale rings present along the circumference could potentially represent hydrophobic domains. The different shapes of HA under different conditions suggest a supramolecular structure. The AFM data of the vertical dimension suggest smaller colloids; this might be due to a size selectivity of the adhesive forces and the attachment process to the mica, favoring smaller particles. The data of the lateral dimension shows a larger spread (up to several $100 \mathrm{~nm}$ ), which cannot be explained by the tip artifact $(\sim 40 \mathrm{~nm})$. Additional studies to determine the changes in the HA structures as a function of solution conditions, is necessary. Other techniques such as small-angle X-ray scattering (SAXS), scanning electron microscopy (SEM) and molecular dynamic may provide information important on HA of the
Amazonian Dark Earths and already are being performed.

\section{ACKNOWLEDGEMENTS}

This work was supported by FAPESP, FINEP, CAPES and $\mathrm{CNPq}$.

\section{REFERENCES}

[1] J. A. Ferreira, O. R. Nascimento, L. Martin-Neto. "Hydrophobic interactions between spin-label 5-SASL and humic acid as revealed by ESR spectroscopy", Environ. Sci. Technol., vol.35, no.4, pp.761-765, 2001.

[2] M. Schnitzer. "Soil organic-matter - the next 75 years ", Soil Sci., vol.151, no.1, pp.41-58, 1991.

[3] F. J. Stevenson. "Humus chemistry: genesis, composition, reactions", 2. ed. New York: J. Wiley, pp.496p, 1994.

[4] K. Ramus, F. D. Kopinke, A. Georgi. "Influence of dissolved humic substances on the mass transfer of organic compounds across the air-water interface", Chemosphere, vol.86, no.2, pp.138-143, 2012.

[5] E. H. Novotny, E. R. Deazevedo, T. J. Bonagamba, T. J. F. Cunha, B. E. Madari, V. D. Benites, M. H. B. Hayes. "Studies of the compositions of humic acids from Amazonian Dark Earth soils", Environ. Sci. Technol., vol.41, no.2, pp.400-405, 2007.

[6] N. Kampf, W. I. Woods, W. Sombroek, D. C. Kern, T. J. F. Cunha. "Classification of Amazonian Dark Earths and other Ancient Anthropic Soils." In Amazonian Dark Earths, Origin, Properties, Management. Kluwer Academic Publishers: Dordrecht,, pp.77-104, 2003.

[7] B. Glaser, E. Balashov, L. Haumaier, G. Guggenberger, W. Zech. "Black carbon in density fractions of anthropogenic soils of the Brazilian Amazon region", Org. Geochem., vol.31, no.7-8, pp.669-678, 2000.

[8] M. L. da Costa, D. C. Kern. "Geochemical signatures of tropical soils with archaeo logical black earth in the Amazon, Brazil", J. Geochem. Explor., vol.66, no.1-2, pp.369-385, 1999.

[9] A. Piccolo, P. Conte. "Molecular size of humic substances. Supramolecular associations versus macromolecular polymers. " Adv. Environ. Res., vol.3, pp.508-521, 2000.

[10] A. Piccolo, S. Nardi, G. Con cheri. "Micelle-like conformation of humic substances as revealed by size exclusion chromatography", Chemosphere, vol.33, no.4, pp.595-602, 1996.

[11] A. Piccolo, S. Nardi, G. Con cheri. "Macromolecular changes of humic substances induced by interaction with organic acids", Eur. J. Soil Sci., vol.47, no.3, pp.319-328, 1996.

[12] D. Milori, L. Martin-Neto, C. Bayer, J. Mielniczuk, V. S. Bagnato. "Humification degree of soil humic acids determined by fluorescence spectroscopy", Soil Sci., vol.167, no.11, pp.739-749, 2002.

[13] H. B. Yu, B. D. Xi, W. C. Ma, D. L. Li, X. S. He. "Fluorescence Spectroscopic Properties of Dissolved Fulvic Acids 
from Salined Flavo-aquic Soils around Wuliangsuhai in Hetao Irrigation District, China", Soil Sci. Soc. Am. J., vol.75, no.4, pp.1385-1393, 2011.

[14] J. J. Alberts, M. Takacs. "Comparison of the natural fluorescence distribution among size fractions of terrestrial fulvic and humic acids and aquatic natural organic matter", Org. Geochem., vol.35, no.10, pp.1141-1149, 2004.

[15] J. J. Alberts, M. Takacs. "Total luminescence spectra of IHSS standard and reference fulvic acids, humic acids and natural organic matter: comparison of aquatic and terrestrial source terms", Org. Geochem., vol.35, no.3, pp.243-256, 2004.

[16] J. D. Mao, N. Chen, X. Y. Cao. "Characterization of humic substances by advanced solid state NMR spectroscopy: Demonstration of a systematic approach", Org. Geochem., vol.42, no.8, pp.891-902, 2011.

[17] C. M. Preston. "Applications of NMR to soil organic matter analysis: History and prospects (vol 161,pg 144, 1996)", Soil Sci., vol.161, no.4, pp.232-232, 1996.

[18] P. Conte, A. E. Berns. "Dynamics of cross polarization in solid state nuclear magnetic resonance experiments of amorphous and heterogeneous natural organic substances", Anal. Sci., vol.24, no.9, pp.1183-1188, 2008.

[19] F. A. M. Cassaro, A. K. Borkowski, L. F. Pires, J. A. Rosa, S D. Saab. "Characterization of a Brazilian clay ey soil submitted to conventional and no-tillage management practices using pore size distribution analy sis", Soil Tillage Res., vol.111, no.2, pp.175-179, 2010,

[20] F. d'Orlye, P. E. Reiller. "Contribution of capillary electrophoresis to an integrated vision of humic substances size and charge characterizations", J. Colloid Interface Sci., vol.368, pp.231-240, 2012.

[21] F. J. Rodriguez, L. A. Nunez. "Characterization of aquatic humic substances", Water Environ. J., vol.25, no.2, pp.163-170, 2011.

[22] S. S. Fong, M. Mohamed. "Chemical characterization of humic substances occurring in the peats of Sarawak, Malaysia", Org. Geoch em., vol.38, no.6, pp.967-976, 2007.

[23] P. S. Redwood, J. R. Lead, R. M. Harrison, I. P. Jones, S. Stoll. "Characterization of humic substances by environmental scanning electron microscopy", Environ. Sci. Technol., vol.39, no.7, pp.1962-1966, 2005.

[24] F. L. Leite, P. S. P. Herrmann. "Application of atomic force spectroscopy (AFS) to studies of adhesion phenomena: a review", J. Adhes. Sci. Technol., vol.19, no.3-5, pp.365-405, 2005.

[25] M. Mertig, D. Klemm, W. Pompe, H. Zanker, M. Bottger. "Scann ing force microscopy of spin-coated humic acid", Surf. Interface Anal., vol.27, no.5-6, pp.426-432, 1999.

[26] M. Plaschke, J. Romer, R. Klenze, J. I. Kim. "In situ AFM study of sorbed humic acid colloids at different $\mathrm{pH}$ ", Colloid Surf. A-Physicochem. Eng. Asp., vol.160, no.3,pp.269-279, 1999.

[27] M. Plaschke, J. Rothe, T. Schafer, M. A. Denecke, K. Dardenne, S. Pompe, K. H. Heise. "Combined AFM and STXM in situ study of the influence of $\mathrm{Eu}(\mathrm{III})$ on the agglomeration of humic acid", Colloid Surf. A-Physicochem. Eng. Asp., vol.197, no.1-3, pp.245-256, 2002.
[28] S. Widayati, K. H. Tan. "Atomic force microscopy of humic acid", Commun. Soil Sci. Plant Anal., vol.28, no.3-5, pp.189-196, 1997.

[29] P. A. Maurice, K. Namjesnik-Dejanovic. "Aggregate structures of sorbed humic substances observed in aqueous solution", Environ. Sci. Technol., vol.33, no.9, pp.1538-1541, 1999.

[30] C. L. Chen, X. K. Wang, H. Jiang, W. P. Hu. "Direct observation of macromolecular structures of hurnic acid by AFM and SEM", Colloid Surf. A-Phy sicochem. Eng. Asp., vol.302, no.1-3, pp.121-125, 2007.

[31] R. S. Swift. "Organic matter characterization", In: Methods of Soil Analysis. Madison: Soil Science Society of America: American Society of Agronomy, Soil Science Society of America Book Series, vol.5. Part 3. Chemical Methods., pp.1011-1020, 1996.

[32] J. A. Ferreira, D. Osiro, P. S. P. Herrmann, L. Martin-Neto. "Atomic force microscopy (AFM) characterization of a tropical soil humic acid", Acta Microscopica, vol.10, pp.43-47, 2001.

[33] O. B. Peersen, X. L. Wu, I. Kustanovich, S. O. Smith. "Variable-amplitude cross-polarization MAS NMR", J. Magn. Reson. Ser. A, vol.104, no.3, pp.334-339, 1993.

[34] I. Horcas, R. Fernandez, J.M. Gomez-Rodriguez, J. Colchero, J. Gomez-Herrero, A. M. Baro. "WSXM: A software for scanning probe microscopy and a tool for nanotechnology", Rev. Sci. Instrum., vol.78, no.1, pp.8, 2007.

[35] E. Balnois, K. J. Wilkinson, Lead, Jr., J. Buffle. "Atomic force microscopy of humic substances: Effects of $\mathrm{pH}$ and ionic strength", Environ. Sci. Technol., vol.33, no.21, pp.3911-3917, 1999.

[36] A. G. Liu, R. C. Wu, E. Eschenazi, K. Papadopoulos. "AFM on humic acid adsorption on mica", Colloid Surf. A-Phy sicochem. Eng. Asp., vol.174, no.1-2, pp.245-252, 2000.

[37] A. Piccolo. "The supramolecular structure of humic substances", Soil Sci., vol.166, no.11, pp.810-832, 2001.

[38] N. Senesi, V. D'Orazio, G. Ricca. "Humic acids in the first generation of EUROSOILS", Geoderma, vol.116, no.3-4, pp.325-344, 2003.

[39] N. Senesi. "Aggregation patterns and macromolecular morphology of humic substances: A fractal approach", Soil Sci., vol.164, no.11, pp.841-856, 1999.

[40] C. E. Clapp, M. H. B. Hayes. "Sizes and shapes of humic substances", Soil Sci., vol.164, no.11, pp.777-789, 1999.

[41] M. H. B. Hay es, C. E. Clapp. "Humic substances: Considerations of compositions, aspects of structure, and environmental influences", Soil Sci., vol.166, no.11, pp.723-737, 2001.

[42] R. S. Swift. "In Hayes, M. H. B., McCarthy, P., Malcolm, R. L., Swift, R. S. (Eds.), Humic Substances. II. In Search of Structure", Wiley, Chichester, pp.449, 1989.

[43] R. Sutton, G. Sposito. "Molecular structure in soil humic substances: The new view", Environ. Sci. Technol., vol.39, no.23, pp.9009-9015, 2005. 